\title{
ANALISIS POLA PEMBELIAN KONSUMEN PADA TRANSAKSI PENJUALAN MENGGUNAKAN ALGORITMA APRIORI
}

\author{
Irsyad Djamaludin \\ Fakultas Teknik dan Ilmu Komputer, Program Studi Sistem Informasi \\ Universitas Komputer Indonesia \\ Email: acquavann@gmail.com \\ Agus Nursikuwagus \\ Fakultas Teknik dan Ilmu Komputer, Program Studi Sistem Informasi \\ Universitas Komputer Indonesia \\ Email: agusnursikuwagus@email.unikom.ac.id
}

\begin{abstract}
ABSTRAK
Penambangan data perlu dilakukan jika informasi disimpan dalam suatu penyimpan. Aktfivitas ini menjadi landasan dalam hal pendukung keputusan untuk pembuat keputusan. Aktivitas yang sudah berjalan adalah informasi transaksi penjualan dan pembelian hanya tersimpan pada repository sebagai suatu laporan saja. Sehingga informasi hanya menjadi data histori yang tidak digunakan. Berdasarkan kejadian ini, maka diperlukan suatu analisis untuk mendukung suatu keputusan. Analisis ini adalah teknik mining dengan menggunakan algoritma Apriori. Tujuan dari penelitian ini adalah mendapatkan pola penjualan dan pembelian suatu produk. Untuk menjawab tujuan maka digunakan algoritma Apriori dengan aturan asosiasi. Penentuan itemset yang digunakan adalah berjumlah 1,2, dan 3 item produk. Sedangkan untuk Minimum Support yang digunakan adalah 30\% dari jumlah transaksi yang ada. Untuk asosiasi antar produk ditentukan dengan confidence sebesar 70\%. Penelitian ini diselesaikan dengan menggunakan UML yang terdiri dari Usecase Diagram, Class Diagram, dan Activty Diagram. Hasil dari penelitian ini adalah perangkat lunak analisis pola penjualan dan pembelian konsumen dengan Algoritma Apriori. Sedangkan keputusan yang diperoleh adalah asosiasi antar produk dengan menggunakan nilai confidence. Untuk Final Rule Association adalah produk bolu cake meses dan bolu cake keju dengan nilai confidence sebesar $84,62 \%$.
\end{abstract}

Kata kunci: pola, pembelian, apriori, transaksi, penjualan, berbasis web.

\begin{abstract}
Data mining is necessary if information is stored in a storage. This activity becomes the foundation in terms of decision support for decision makers. The activity that has been running is the sales and purchase transaction information only stored on the repository as a report only. So the information only becomes unused history data. Based on this facts, an analysis is needed to support a decision. This analysis is a mining technique using Apriori algorithm. The purpose of this research is to retrieve the pattern of sale and purchase of a product. To answer the purpose then used Apriori algorithm with association rules. The itemset determination used is 1,2, and 3 product items. As for Minimum Support used is $30 \%$ of the number of transactions. For associations between products is determined with a confidence of $70 \%$. This research was completed by using UML consisting of Usecase Diagram, Class Diagram, and Activty Diagram. The result of this research is software analysis of sales pattern and consumer purchase with a priori algorithm. While the decision obtained is the association between products using the value of confidence. For Final Rule Association is messes cake and cheese cake with value of confidence equal to $84,62 \%$.
\end{abstract}

Keywords: pattern, purchase, apriori, transaction, sales, web-based.

\section{PENDAHULUAN}

Perubahan kondisi pada suatu perusahaan baik yang ada di lingkungan dan luar perusahaan tentu sangat penting untuk bisa dihadapi. Pengambilan keputusan bisnis yang cepat dan tepat adalah salah satu solusi agar perusahaan tetap bisa berkembang serta bisa beradaptasi terhadap perubahan - perubahan yang ada. 
Data transaksi penjualan adalah salah satu hal yang bisa dimanfaatkan untuk suatu pengambilan keputusan bisnis. Kebanyakan data transaksi penjualan tidak dimanfaatkan kembali, dan hanya disimpan saja sebagai arsip serta hanya dijadikan untuk pembuatan suatu laporan penjualan. Data mining adalah salah satu ilmu yang dapat diterapkan dalam kasus seperti ini. Transaksi penjualan yang tidak dimanfaatkan dengan baik tersebut bisa digali dan diolah kembali menjadi suatu informasi yang bermanfaat dengan menggunakan teknik data mining. Menggunakan salah satu metode data mining, yaitu Algoritma Apriori, data transaksi penjualan dapat diolah kembali sehingga bisa menghasilkan suatu pola pembelian konsumen. Pola pembelian konsumen inilah yang nantinya akan membantu owner untuk membuat suatu keputusan bisnis.

Roseberry adalah perusahaan rumahan yang bergerak di bidang industri makanan, yang dimana aktivitas utamanya ialah memproduksi dan menjual bolu serta menjual berbagai kue basah dan cemilan lainnya. Sama seperti perusahaan lainnya, Roseberry tidak memanfaatkan kembali data transaksi penjualan yang dihasilkan dari aktivitas penjualannya. Data tersebut hanya digunakan sebagai acuan untuk membuat laporan penjualan serta menjadi arsip saja

Adapun penelitian terdahulu yang menjadi salah satu acuan dari penelitian ini ialah penelitian yang dilakukan oleh Agus Nursikuwagus dan Tono Hartono dengan judul 'Implementasi Algoritma Apriori untuk analisis transaksi dengan berbasis web' bertujuan untuk merancang suatu aplikasi yang didasari algoritma Apriori untuk menganalisa transaksi. Persaingan yang begitu ketat membuat pelaku harus pintar dalam menganalisis pasar. Selain itu, penting bagi pelaku usaha untuk menganalisa ketersediaan produk agar kebutuhan pelanggan terpenuhi. Salah satu solusi yang bisa dilakukan ialah dengan menganalisa data transaksi yang ada dengan sebuah aplikasi data mining. [1]

Penelitian yang dilakukan oleh Heroe Santoso, I Putu Hariyadi serta Prayitno yang bertujuan untuk menganalisa data transaksi penjualan guna menemukan pola pembelian produk untuk mengetahui keterkaitan antar suatu produk, yang dimana pola tersebut bisa digunakan untuk penempatan produk serta untuk merancang suatu diskon untuk produk tersebut. Adapun solusi dari masalah ini ialah membuat aplikasi data mining analisa pola pembelian produk dengan metode algoritma Apriori. [2]

Penelitian yang dilakukan oleh Muhammad Thoriq Agung dan Bowo Nurhadiyono untuk mengatur penempatan produk menggunakan algoritma Apriori' yang bertujuan untuk mengetahui produk mana yang dibeli secara bersamaan sehingga bisa digunakan untuk mengatur penempatan produk. Solusi yang diberikan ialah dengan menganalisis data perusahaan, khususnya data transaksi penjualan dengan menggunakan aplikasi data mining [3].

Berdasarkan paparan di atas, maka penelitian ini bermaksud untuk membuat suatu aplikasi untuk mengolah suatu data transaksi penjualan sehingga dapat menghasilkan suatu informasi mengenai pola pembelian konsumen yang nantinya digunakan untuk membantu owner untuk melakukan pengambilan keputusan bisnis. Aplikasi yang dibuat merupakan aplikasi berbasiskan web dengan metode Algorithm Apriori.

\section{METODOLOGI PENELITIAN}

Metode penelitian adalah prosedur atau cara yang harus dipilih untuk melakukan suatu penelitian. Metode penelitian merupakan cara utama yang digunakan peneliti untuk mencapai tujuan dan menentukan jawaban atas masalah yang diajukan [4]. Penelitian ini termasuk kedalam metode penelitian tindakan serta desain penelitian kuantitatif. Adapun metode pengembangan sistem yang dipakai ialah Prototype. Prototype adalah satu versi dari sebuah sistem potensial yang memberikan ide dari para pengembang dan calon pengguna, bagaimana sistem akan berfungsi desain berorientasi objek adalah cara baru dalam memikirkan satu masalah dengan menggunakan model yang dibuat menurut konsep sekitar dunia nyata. Dasar pembuatan adalah objek, yang merupakan kombinasi antara struktur data dan perilaku dalam satu entitas [6].

\subsection{Data Mining Dan Algoritma Apriori}

Secara sederhana data mining adalah penambangan atau penemuan informasi baru dengan mencari suatu pola atau aturan tertentu dari sejumlah data yang sangat besar [7]. Algoritma Apriori adalah salah satu algoritma yang melakukan pencarian frequent itemset dengan menggunakan teknik association rule. Algortima Apriori menggunakan pengetahuan sebelumnya dari suatu itemset dengan frekuensi kemunculan yang sering atau juga yang bisa disebut frekuent itemset [8]. Berikut algoritma umum dari Apriori. 
Algoritma Apriori (T,E)

1. $\mathrm{L}_{1} \leftarrow$ Large 1 - itemsets $\}$

2. $\mathrm{K} \leftarrow 2$

3. While $\mathrm{L}_{\mathrm{k}-1} \neq 0$

3.1. $\mathrm{C}_{\mathrm{k}} \leftarrow\left\{\mathrm{a} \cup\{\mathrm{b}\} \mid \mathrm{a} \in \mathrm{L}_{\mathrm{k}-1} \wedge \mathrm{b} \notin \mathrm{a}\right\}-\left\{\mathrm{c} \mid\{\mathrm{s}|\mathrm{s} \subseteq \mathrm{c} \wedge| \mathrm{s} \mid=\mathrm{k}-1\}\right.$ is not subset $\left.\mathrm{L}_{\mathrm{k}-1}\right\}$

3.2. for transactions $\mathrm{t} \in \mathrm{T}$

3.2.1. $\mathrm{C}_{\mathrm{t}} \leftarrow\left\{\mathrm{c} \mid \mathrm{c} \in \mathrm{C}_{\mathrm{k}} \wedge \mathrm{c} \subseteq \mathrm{t}\right\}$

3.2.1.1. for candidates $\mathrm{c} \in \mathrm{C}_{\mathrm{t}}$

3.2.1.1.1. $\quad$ count $[\mathrm{c}] \leftarrow \operatorname{count}[\mathrm{c}]+1$

3.2. $\mathrm{Lk} \leftarrow\left\{\mathrm{c} \mid \mathrm{c} \in \mathrm{C}_{\mathrm{k}} \wedge \operatorname{count}[\mathrm{c}] \geq \varepsilon\right\}$

3.3. $\mathrm{k} \leftarrow \mathrm{k}+1$

4. Return $\mathrm{U}_{k} L k$

Keterangan : untuk T merupakan kumpulan data transaksi dari tabel/database. " $\varepsilon$ ” merupakan ambang batas untuk item support. Ck adalah kandidat pada tahap k. Count[c] adalah jumlah kandidat c. "c" merupakan kandidat itemset

\subsection{PHP, MySql, Dan HTML}

PHP adalah kependekan dari PHP Hypertext Preprocessor, bahasa interpreter yang mirip dengan Bahasa $C$ dan Perl yang memiliki kesederhanaan perintah. PHP dapat digunakan bersama dengan $H T M L$ sehingga memudahkan dalam pembangunan aplikasi web dengan cepat [9]. MySQL adalah sistem manajemen database SQL yang bersifat Open Source dan paling populer saat ini. Sistem Database MySQL mendukung beberapa fitur seperti multithreaded, multi-user, dan SQL database managemen sistem (DBMS) [10]. HTML adalah kepanjangan atau singkatan dari Hyper Text Markup Language. Setiap penjelajhan di internet, membuka website apapun, pasti akan bertemu dengan HTML. Hal ini dikarenakan semua website yang ada di internet, dibuat dengan menggunakan bahasa markup HTML [11].

\section{HASIL DAN PEMBAHASAN}

\subsection{Hasil}

Pada hasil ini akan dipaparkan implementasi dari algoritma Apriori pada suatu aplikasi berbasis web. Gambar 1, menunjukan form penetapan transaksi mana yang akan dianalisis berdasarkan tanggal, minimal itemset, minimal support, minimal confidence, serta Batasan final association rule.

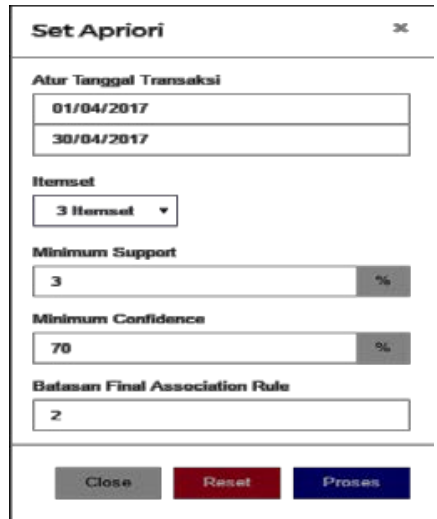

\section{Gambar 7. Form Fungsi Penetapan Apriori}

Pada gambar 2 menunjukan form hasil eksekusi itemset 1 . Adapun untuk proses perhitungan itemset 1 tidak lebih dari 1 detik. Pada gambar 3, menunjukan form hasil eksekusi itemset 2. Adapun untuk proses perhitungan itemset 2 tidak lebih dari 1 detik. Pada gambar 4, menunjukan form hasil eksekusi itemset 3. Adapun untuk proses perhitungan itemset 3 tidak lebih dari 1 detik. Pada gambar 3 dan 4 , itemset 3 dan 3 minimal support dan confidencenya sudah diseleksi. 


\begin{tabular}{|c|c|c|c|c|c|c|c|c|c|}
\hline \multicolumn{10}{|c|}{ Frequent 1 ltemset (Waktu : 0 detk) } \\
\hline \multirow{2}{*}{$\begin{array}{l}\text { Show } 10 \\
\text { No } \quad \text { 口 }\end{array}$} & \multirow{2}{*}{$\begin{array}{l}\text { entries } \\
\text { NAMA PRODUK }\end{array}$} & \multicolumn{8}{|c|}{ Search: } \\
\hline & & D & \multicolumn{2}{|l|}{ JUMLAH PENJUALAN* } & 口 & \multicolumn{4}{|c|}{ SUPPORT } \\
\hline 1 & (BRB0001)Donat Dus & & \multicolumn{3}{|l|}{39 dari 245} & \multicolumn{4}{|c|}{$15.92 \%$} \\
\hline 2 & (BRBO002)Roti Unyil & & \multicolumn{3}{|l|}{11 dari 245} & \multicolumn{4}{|c|}{$4.49 \%$} \\
\hline 3 & (BRB0003)Bolu Peuyeum & & \multicolumn{3}{|l|}{20 dari 245} & \multicolumn{4}{|c|}{$8.16 \%$} \\
\hline 4 & (BRB0004)Bolu Coklat & & \multicolumn{3}{|l|}{34 dari 245} & \multicolumn{4}{|c|}{$13.88 \%$} \\
\hline 5 & (BRB0005)Bolu Hias Mini & & \multicolumn{3}{|l|}{37 dari 245} & \multicolumn{4}{|c|}{$15.1 \%$} \\
\hline 6 & (BRB0006)Bolu Pisang & & \multicolumn{3}{|l|}{8 dari 245} & \multicolumn{4}{|c|}{$3.27 \%$} \\
\hline 7 & (BRB0008)Bolu Nanas & & \multicolumn{3}{|l|}{13 dari 245} & \multicolumn{4}{|c|}{$5.31 \%$} \\
\hline 8 & (BRB0009)Bolu Hias CM & & \multicolumn{3}{|l|}{31 dari 245} & \multicolumn{4}{|c|}{$12.65 \%$} \\
\hline 9 & (BRB0010)Bolu Gulung Meses & & \multicolumn{3}{|l|}{32 dari 245} & \multicolumn{4}{|c|}{$13.06 \%$} \\
\hline 10 & (BRBO011)Bolu Gulung Mini & & \multicolumn{3}{|l|}{40 dari 245} & \multicolumn{4}{|c|}{$16.33 \%$} \\
\hline \multicolumn{4}{|c|}{ Showing 1 to 10 of 34 entries } & revious & 1 & 2 & 3 & 4 & Next \\
\hline
\end{tabular}

Gambar 8. Form Hasil Eksekusi Dari Itemset 1

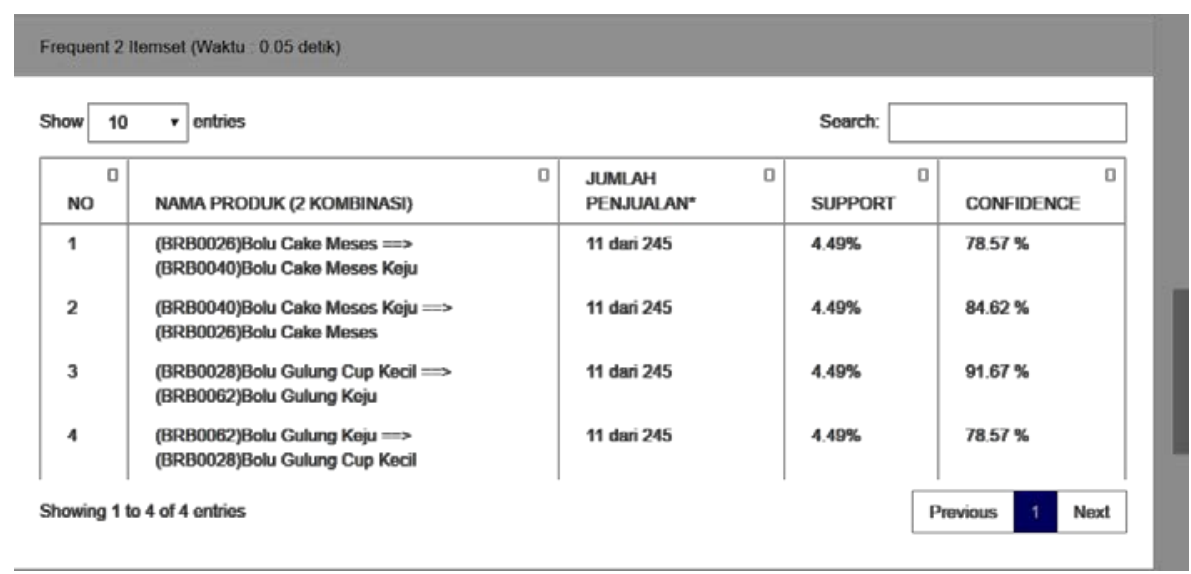

Gambar 9. Form Hasil Eksekusi Dari Itemset 2

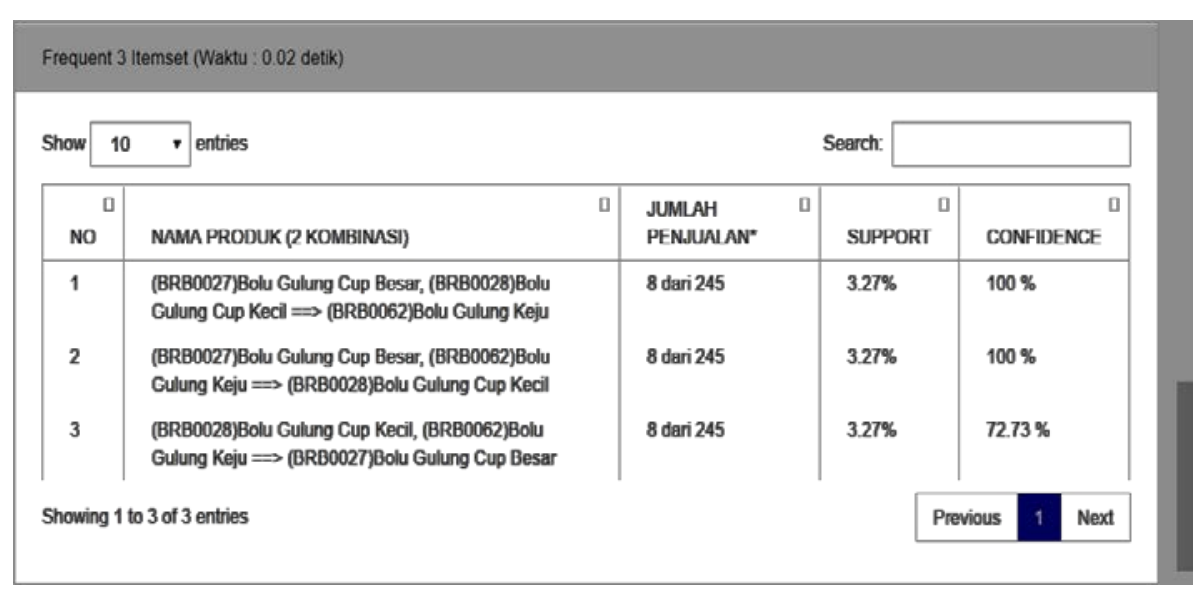

\section{Gambar 10. Form Hasil Eksekusi Dari Itemset 2}

Pada gambar 5 menunjukan tabel final association rule. Adapun untuk proses perhitungan itemset 3 tidak lebih dari 1 detik. Atribut support x confidence dirubah menjadi atribut point. Dikarenakan batasan final association rule yang telah ditentukan ialah 2 aturan, maka hasil yang diperoleh ialah seperti yang ada pada gambar 2. Aturannya ialah sebagai berikut :

a) Jika membeli produk (BRB0028)Bolu Gulung Cup Kecil maka akan membeli (BRB0062)Bolu Gulung Keju. dengan support sebesar 4.49\% atau dengan kata lain dengan jumlah penjualan 11 dari 245 penjualan. Confidence sebesar $\mathbf{9 1 . 6 7 \%}$ serta point sebesar $\mathbf{4 . 1 2} \%$

b) Jika membeli produk (BRB0040)Bolu Cake Meses Keju maka akan membeli (BRB0026)Bolu Cake Meses. Dengan support sebesar $\mathbf{4 . 4 9 \%}$ atau dengan kata lain dengan jumlah penjualan 11 dari 245 penjualan. Confidence sebesar $84.62 \%$ serta point sebesar $\mathbf{3 . 8 \%}$ 


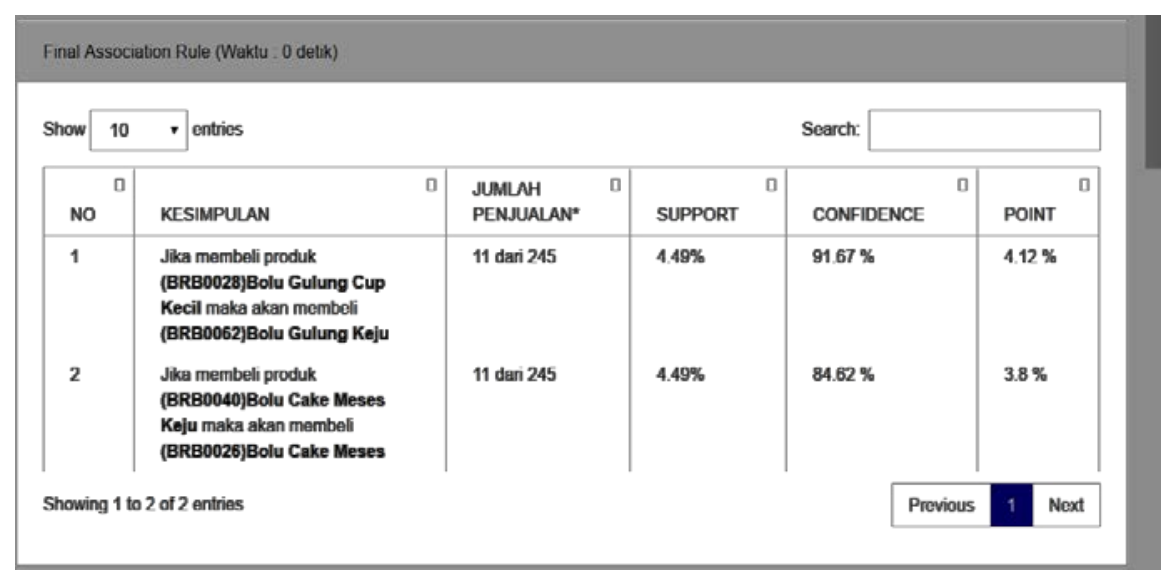

Gambar 11. Tabel Final Association Rule

\subsection{Pembahasan}

Seperti yang telah dijelaskan dalam pendahuluan, data transaksi penjualan yang ada di Roseberry tidak diolah dan dianalisa lebih lanjut, sehingga data tersebut belum dimanfaatkan dengan baik dan hanya dipakai untuk pembuatan laporan penjualan serta sebagai arsip saja. Tujuan dari jurnal ini ialah untuk mendapatkan suatu informasi mengenai pola pembelian konsumen yang dimana informasi tersebut ditujukan untuk membantu owner dalam membuat suatu keputusan bisnis dengan menggunakan teknik data mining, tepatnya menggunakan teknik algoritma Apriori dan association rule. Analisis tersebut dibantu dengan menggunakan suatu aplikasi berbasis web.

Sumber data yang didapat dalam penelitian ini merupakan data transaksi yang terjadi di Roseberry selama bulan April 2017. Adapun detail informasi mengenai data transaksi yang digunakan dapat dilihat dalam tabel 1. Pada tabel 2, contoh sebagian data yang belum diseleksi dan diekstrak ke dalam bentuk file .cSV untuk diimport kedalam database. Data transaksi bulan April 2017 memiliki banyak transaksi sebanyak 282 transaksi.

Tabel 1. Struktur data transaksi

\begin{tabular}{lll}
\hline \multicolumn{1}{c}{ Dokumen } & & \multicolumn{1}{c}{ Keterangan } \\
\hline Laporan & Deskripsi : & Data ini berisi mengenai transaksi yang terjadi di Roseberry \\
Penjualan & Fungsi : & Untuk mengetahui pola pembelian konsumen \\
April 2017 & Format : & Microsoft excel (.xls) \\
\hline
\end{tabular}

Tabel 2. Contoh format data transaksi awal

\begin{tabular}{l|l|l|l|l|l|l}
\hline $\begin{array}{l}\text { Tanggal } \\
* * * \text { Kode }\end{array}$ & $\begin{array}{l}\text { KODE } \\
\text { BARANG }\end{array}$ & $\begin{array}{l}\text { PEL/MEM/ } \\
\text { CAB/SALES }\end{array}$ & $\begin{array}{l}\text { OPERATOR } \\
\text { SATUAN }\end{array}$ & $\begin{array}{l}\text { PEMBAYARAN } \\
\text { QTY }\end{array}$ & $\begin{array}{l}\text { HRG } \\
\text { JUAL }\end{array}$ & $\begin{array}{l}\text { DISKON } \\
\text { JULAH }\end{array}$ \\
\hline 1-Apr-17 & BRB0011 & $\begin{array}{l}\text { Bolu Gulung } \\
\text { Mini }\end{array}$ & Dus & 10 & 10,000 & 100,000 \\
\hline$* * *$ & BRB0014 & $\begin{array}{l}\text { Bolu Blackforest } \\
\text { Mini }\end{array}$ & Dus & 8 & 12,000 & 96,000 \\
\hline$* * *$ & BRB0001 & Donut Dus & BH & 2 & 8,000 & 16,000 \\
\hline
\end{tabular}

Rangkaian dalam data mining, terdiri dari preprocessing, mining, dan post mining. Preprocessing data adalah hal yang harus dilakukan dalam proses data mining, karena tidak semua data atau atribut data digunakan dalam proses data mining. Proses ini dilakukan agar data yang akan digunakan sesuai dengan kebutuhan.

\subsubsection{Preprocessing}

Preprocessing data adalah hal yang harus dilakukan dalam proses data mining, karena tidak semua data atau atribut data dalam data digunakan dalam proses data mining. Proses ini dilakukan agar data yang akan digunakan sesuai dengan kebutuhan. Adapun tahapan-tahapan preprocessing data dalam penelitian ini adalah sebagai berikut :

a) Ekstrasi Data

Data awal seperti pada table 2, akan diekstraksi ke dalam file .csv serta diberi format baru agar data terorganisir dengan baik. Berikut tabel 3, contoh dari data transaksi yang sudah diekstrak dan diberi format baru. 
Tabel 3. Contoh data transaksi yang telah diekstrak

\begin{tabular}{cccccc}
\hline KD-TRS & TGL & KD-BRG & SATUAN & QYT & HRG-SAT \\
\hline FJ-0104170184 & $2017-04-01$ & BRB0011 & 0 & 10 & 0 \\
FJ-0104170184 & $2017-04-01$ & BRB0014 & 0 & 8 & 0 \\
FJ-0104170184 & $2017-04-01$ & BRB0001 & 0 & 2 & 0 \\
FJ-0104170184 & $2017-04-01$ & BRB0001 & 0 & 24 & 0 \\
FJ-0104170185 & $2017-04-01$ & BRB0003 & 0 & 10 & 0 \\
FJ-0104170185 & $2017-04-01$ & BRB0010 & 0 & 10 & 0 \\
\hline
\end{tabular}

b) Pembersihan Data

Pada tahap ini dilakukan pembersihan data atau menghilangkan data yang tidak dibutuhkan dalam proses analisis. Dalam kasus ini ialah menghilangkan data barang seperti kresek, lilin, dan lain - lain. dari data 282 transaksi, selama proses pembersihan data tersebut, data transaksi menjadi 245 transaksi.

\subsubsection{Perhitungan Apriori}

Dalam tabel 4 adalah transaksi penjualan selama bulan April 2017 yang telah melewati proses preprocessing data.

Tabel 4. Data transaksi

\begin{tabular}{|c|c|c|}
\hline No & Nota & Nama Barang \\
\hline 1 & FJ-0104170184 & Bolu Gulung Mini, Bolu Blackforest Mini, Donat Dus \\
\hline 2 & FJ-0104170185 & Bolu Blackforest Mini, Bolu Gulung Meses, Bolu Peuyeum, Donat Dus \\
\hline 3 & FJ-0104170186 & Bolu Blackforest Mini, Bolu Gulung Mini, Bolu Ubi \\
\hline 4 & FJ-0204170134 & $\begin{array}{l}\text { Bolu Blackforest 65, Bolu Brownies Bakar, Bolu Hias CM, Bolu Hias } \\
30\end{array}$ \\
\hline 5 & FJ-0204170135 & Bolu Gulung Cup Besar, Bolu Brownies Cup Panjang \\
\hline $\begin{array}{c}\cdots \\
245\end{array}$ & FJ-3004170466 & $\begin{array}{l}\text { Bolu Peuyeum, Bolu Cake Sedang, Bolu Coklat, Bolu Ketan Cup, Bolu } \\
\text { Hias CM, Bolu Cake Kecil, Bolu Coklat 46, Bolu Ketan Kukus, Bolu } \\
\text { Gulung Mini, Bolu Brownies Kukus }\end{array}$ \\
\hline
\end{tabular}

Dari data transaksi tersebut ditentukan itemsetnya 3, minimal support $=3 \%$, minimal confidence $=$ $70 \%$, serta batasan final association rule $=2$. Setelah dilakukan proses perhitungan minimal support=3\%. Untuk menghitung support pada itemset 1 adalah sebagai berikut :

$\frac{\sum \text { Transaksimengandung produk A }}{\sum \text { Transaksi }} \times \mathbf{1 0 0 \%}$

Dari transaksi penjualan diketahui ada 34 dari 43 produk yang memenuhi minimal support 3\%. Berikut adalah itemset 1 yang memenuhi minimal support.

Tabel 5. Hasil seleksi support dari setiap produk dari persamaan (1)

\begin{tabular}{llll}
\hline No & Itemset 1 & Jumlah Penjualan & Support \\
\hline 1 & Donat Dus & 39 dari 245 & $15.92 \%$ \\
2 & Roti Unyil & 11 dari 245 & $4.49 \%$ \\
3 & Bolu Peuyeum & 20 dari 245 & $8.16 \%$ \\
4 & Bolu Coklat & 34 dari 245 & $13.88 \%$ \\
5 & Bolu Hias Mini & 37 dari 245 & $15.1 \%$ \\
6 & Bolu Pisang & 8 dari 245 & $3.27 \%$ \\
7 & Bolu Nanas & 13 dari 245 & $5.31 \%$ \\
8 & Bolu Hias CM & 31 dari 245 & $12.65 \%$ \\
9 & Bolu Gulung Meses & 32 dari 245 & $13.06 \%$ \\
$\ldots$ & .. & & $\ldots$ \\
34 & Bolu Hias 30 & 34 dari 245 & $13.88 \%$ \\
\hline
\end{tabular}

Langkah selanjutnya ialah membentuk itemset 2 dengan mengkombinasikan produk-produk pada itemset 1 . Perhitungan support pada itemset 2 adalah sebagai berikut : 


\section{$\frac{\sum \text { Transaksi mengandung produk A dan B }}{\sum \text { Transaksi }} \times 100 \%$}

Dari hasil kombinasi tersebut, dihasilkan 67 dari 561 kombinasi yang memenuhi minimal support. Pada table 6 adalah hasil itemset 2 yang memenuhi minimal support.

Tabel 6. Tabel itemset 2 memenuhi minimal support (2)

\begin{tabular}{clll}
\hline No & Itemset 2 & Jumlah Penjualan & Support \\
\hline 1 & Donat Dus $==>$ Bolu Gulung Mini & 8 dari 245 & $3.27 \%$ \\
2 & Donat Dus $==>$ Bolu Blackforest Mini & 13 dari 245 & $5.31 \%$ \\
3 & Bolu Coklat ==> Bolu Hias CM & 10 dari 245 & $4.08 \%$ \\
4 & Bolu Coklat $==>$ Bolu Gulung Meses & 9 dari 245 & $3.67 \%$ \\
5 & Bolu Coklat $==>$ Bolu Gulung Mini & 13 dari 245 & $5.31 \%$ \\
$\ldots$ & $\ldots$ & $\ldots$ & $\ldots$ \\
67 & Bolu Coklat 46 ==> Bolu Hias 30 & 15 dari 245 & $6.12 \%$ \\
\hline
\end{tabular}

Sama seperti langkah sebelumnya, dilakukan kombinasi itemset 2 sehingga dapat terbentuk itemset 3. Untuk perhitungan support pada itemset 3 ini ialah sebagi berikut:

$\frac{\text { ETransaksi mengandung produk A,B dan } C}{\sum \text { Transaksi }} \times 100 \%$

Dari kombinasi tersebut terdapat 3 dari 157 kombinasi yang memenuhi nilai minimal support. Berikut adalah itemset 2 yang memenuhi minimal support.

Tabel 7. Tabel itemset 3 yang telah memenuhi minimal support (3)

\begin{tabular}{clll}
\hline No & Itemset 3 & Jumlah Penjualan & Support \\
\hline \multirow{2}{*}{1} & Bolu Brownies Kukus, Bolu Cake Kecil ==> Bolu Cake & 8 dari 245 & $3.27 \%$ \\
2 & Sedang & 9 dari 245 & $3.67 \%$ \\
3 & Bolu Cake Kecil, Bolu Cake Sedang ==> Bolu Coklat 46 & $3.27 \%$ \\
\hline
\end{tabular}

Dikarenakan itemset 3 tidak bisa dikombinasikan kembali serta Batasan itemset yang ditentukan adalah 3 itemset, maka proses perhitungan support dan pembentukan itemset dihentikan. Langkah selanjutnya ialah menghitung confidence. Sebelum menghitung confidence dilakukan terlebih dahulu pertukaran itemset. Misal suatu kombinasi pada itemset 2 yaitu $\mathbf{A} \rightarrow \mathbf{B}$, maka dibalik menjadi $\mathbf{B} \rightarrow \mathbf{A}$. contoh lainnya ialah suatu kombinasi pada itemset 3, yaitu $\mathbf{A , B} \rightarrow \mathbf{C}$, itemset tersebut bisa dibalik menjadi $\mathbf{A}, \mathbf{C} \rightarrow \mathbf{B}$ dan $\mathbf{B}, \mathbf{C} \rightarrow \mathbf{A}$. nilai support pada masing masing itemset tersebut tetap sama, akan tetapi kemungkinan nilai confidence bisa berbeda. Hal tersebut juga agar dapat diketahui mana nilai confidence yang terbesar dari tiap itemset tersebut. Adapun untuk perhitungan confidence untuk itemset 2 ialah sebagai berikut :

$\frac{\text { KTransaksi mengandung produk A dan B }}{\sum \text { Transaksi A }} \times 100 \%$

Sedangkan untuk perhitungan confidence pada itemset 3 ialah sebagai berikut :

\section{ETransaksi mengandung produk $A, B$ dan $C$ X $100 \%$}

Pada tabel 8 menunjukan itemset 2 yang telah dihitung nilai confidence dan telah diseleksi oleh minimal confidence-nya.

Tabel 8. Tabel itemset 2 yang telah memenuhi minimal confidence (4)

\begin{tabular}{clll}
\hline No & Itemset & Support & Confidence \\
\hline 1 & Bolu Cake Meses ==> Bolu Cake Meses Keju & $4.49 \%$ & $78.57 \%$ \\
2 & Bolu Cake Meses Keju ==> Bolu Cake Meses & $4.49 \%$ & $84.62 \%$ \\
3 & Bolu Gulung Cup Kecil ==> Bolu Gulung Keju & $4.49 \%$ & $91.67 \%$ \\
4 & Bolu Gulung Keju ==> Bolu Gulung Cup Kecil & $4.49 \%$ & $78.57 \%$ \\
\hline
\end{tabular}


Tabel 9 menunjukan itemset 3 yang telah dihitung nilai confidence dan telah diseleksi oleh minimal confidencenya.

Tabel 9. Tabel itemset 3 yang telah memenuhi minimal confidence (5)

\begin{tabular}{clll}
\hline No & Itemset & Support & Confidence \\
\hline 1 & $\begin{array}{l}\text { Bolu Gulung Cup Besar, Bolu Gulung Cup Kecil ==> } \\
\text { Bolu Gulung Keju }\end{array}$ & $3.27 \%$ & $100 \%$ \\
2 & $\begin{array}{l}\text { Bolu Gulung Cup Besar, Bolu Gulung Keju ==> } \\
\text { Bolu Gulung Cup Kecil } \\
3\end{array}$ & $\begin{array}{l}\text { Bolu Gulung Cup Kecil, Bolu Gulung Keju ==> Bolu } \\
\text { Gulung Cup Besar }\end{array}$ & $3.27 \%$ \\
\hline
\end{tabular}

Selanjutnya ialah membuat tabel Association Rule, dimana support dan confidence dari masing masing itemset dikalikan agar dapat mengetahui mana association rule yang paling besar nilanya. Dikarenakan Batasan final association rule yang ditentukan hanya 2, maka aturan yang diambil hanya 2 aturan tertinggi seperti yang ada pada tabel 3.

Tabel 10. Tabel final association rule

\begin{tabular}{cllll}
\hline No & Itemset & Support & Confidence & Support x Confidence \\
\hline 1 & $\begin{array}{l}\text { Bolu Gulung Cup Kecil ==> Bolu } \\
\text { Gulung Keju }\end{array}$ & $4.49 \%$ & $91.67 \%$ & $4.12 \%$ \\
2 & $\begin{array}{l}\text { Bolu Cake Meses Keju ==> Bolu } \\
\text { Cake Meses }\end{array}$ & $4.49 \%$ & $84.62 \%$ & $3.8 \%$ \\
\hline
\end{tabular}

\section{KESIMPULAN}

Penelitian dapat disimpulkan bahwa data mining dan teknik algoritma Apriori ini dapat diimplementasikan terhadap data transaksi penjualan, salah satunya untuk mendapatkan pola pembelian konsumen. Pola yang diperoleh, akan menghasilkan suatu rule atau aturan mengenai keterkaitan dari suatu produk.

Hasil atau rule yang didapatkan dipengaruhi oleh batasan yang ditentukan, baik banyaknya data, batasan itemset, batasan minimal support dan confidence, serta batasan final association rule yang ditetapkan secara manual. Hasil yang didapatkan juga dipengaruhi oleh data transaksi penjualannya, terutama varian produk yang ada dalam setiap transaksi.

Pada kasus ini, produk yang ada dalam data transaksi penjualan yang dipakai untuk dianalisis ini sangat bervarian, faktor ini akan mempengaruhi nilai support yang akan dihasilkan dalam setiap itemsetnya.

\section{DAFTAR PUSTAKA}

[1] Nursikuwagus, A., \& Hartono, T. (2016). Implementasi Algoritma Apriori Untuk Analisis Penjualan Dengan Berbasis Web. Simetris: Jurnal Teknik Mesin, Elektro dan Ilmu Komputer, 7(2), 701-706.

[2] Santoso, H., Hariyadi, I. P., \& Prayitno, P. (2016). Data Mining Analisa Pola Pembelian Produk Dengan Menggunakan Metode Algoritma Apriori. Semnasteknomedia Online, 4(1), 3-7.

[3] Muhammad, A. T. (2015). Penerapan Data Mining Pada Data Transaksi Penjualan Untuk Mengatur Penempatan Barang Menggunakan Algoritma Apriori. Skripsi, Fakultas Ilmu Komputer Universitas Dian Nuswantoro.

[4] Nazir, Mohammad. (1988). Metode Penelitian. Jakarta: Ghalia Indonesia

[5] Darmawan, et al. (2013). Sistem Informasi Manajemen. Bandung: PT Remaja Rosdakarya.

[6] Divayana, Hendra. (2010). Konsep OOAD. Jakarta: STMIK Eresha.

[7] Davies, B. (2004). Database Systems 3rd Edition. Basingstoke, UK : Palgrave.

[8] Pramudiono, I (2007). Pengantar Data mining : Menambang Permata Pengetahuan di Gunung Data. http://www.ilmu computer.org/wp-content/uploads/ 2006/08/iko-datamining.

[9] Micheline, Kamber dan Jiawei, Han. (2006). Data mining: Concepts and Technique. San Francisco: Diane Cerra.

[10] Iswanto, ST. (2007). Membangun Aplikasi Berbasis PHP 5 dan Firebird 1,5. Yogyakarta : ANDI

[11] Agil Wirawan Faiz. (2015). Pengertian HTML, Fungsi HTML, serta Sejarah HTML. http://www.burung-net.com/2015/05/pengertian-html-fungsi-html-serta-sejarah-html.html 